\title{
Association of Metabolic Syndrome in Obstructive Sleep Apnea Patients: An Experience from Zonal Tertiary Care Hospital in Eastern India
}

\author{
Santosh Kumar Singh, Ajai Kumar Tentu' ${ }^{1}$, Sarvinder Singh², Nidhi Singh ${ }^{3}$, Chinmaya Dash ${ }^{3}$, Vani Singh ${ }^{4}$, Rongala Laxmivandana ${ }^{5}$, Rachana Warrier ${ }^{3}$ \\ Department of Medicine, Command Hospital, Udhampur, Jammu and Kashmir, Departments of ${ }^{1}$ Pulmonary Medicine and ${ }^{3}$ Medicine, Military Hospital, Namkum, \\ ${ }^{4}$ Department of Radiation Oncology, RIMS, ${ }^{5}$ Department of Life Sciences, CUJ, Ranchi, Jharkhand, ${ }^{2}$ Department of Medicine, Military Hospital, Gwalior, Madhya \\ Pradesh, India
}

\section{Abstract}

Introduction: Even in a tertiary health-care setting, obstructive sleep apnea (OSA) patients often remain underdiagnosed. OSA and metabolic syndrome (MS) share many essential cardiovascular risk factors, including obesity, hypertension, and insulin resistance. Despite numerous studies, the relationship between OSA and MS still remains debatable. Aim: The purpose of our study was to see how frequently MS occurred in OSA patients and also if the presence of MS had any correlation with age, sex, or severity of OSA. Methodology: This cross-sectional study included 50 OSA patients being evaluated on outpatient department basis. All the patients were screened with detailed history; examination; hematological, biochemical parameters; and polysomnography. Results: In this study, out of 50 OSA patients, 41 were male and 9 were female; with age, body mass index (BMI), Apnea-Hypopnea Index (AHI), neck circumference, and waist circumference having mean of 42.5 years, $27.028 \mathrm{~kg} / \mathrm{m}^{2}, 33.49 / \mathrm{h}, 39.7 \mathrm{~cm}$, and 37.23 inch, respectively. Out of 28 obese patients, 22 had AHI $>30$ and 6 had AHI $<30.31(62 \%)$ OSA patients were found to have MS, of which 27 were male and 4 were female. Pearson's bivariate correlation has also shown statistically significant association between AHI score and BMI value $(P=0.01)$. Conclusion: Our study has shown a positive association between OSA and MS and OSA may represent an important risk factor for development of MS. Therefore, it is prudent for clinicians to systematically evaluate the presence of metabolic abnormalities in OSA patients and vice versa.

Keywords: Insulin resistance, metabolic syndrome, obstructive sleep apnea, polysomnography, syndrome Z

\section{INTRODUCTION}

Obstructive sleep apnea (OSA) is a condition involving repetitive obstruction of upper airways during sleep, resulting in hypopnea or apnea. These include either symptoms of nocturnal breathing disturbances such as snoring, gasping or breathing pause while sleeping or daytime sleepiness, and fatigue despite ample sleep often unexplained by other medical problems. ${ }^{[1,2]}$ OSA remains a difficult and underdiagnosed clinical condition, ultimately leading to health-care burden. ${ }^{[3]}$ A community-based survey conducted in our country reported the prevalence of OSA around $9.3 \% \cdot{ }^{[4]}$ OSA was observed to be prevalent in the range between $4 \%$ and $24 \%$ for men and $2 \%-16 \%$ for women.

People aged more than 40 years are more prone to OSA ${ }^{[5]}$ It is also approximated that 1 out of 5 adults has mild symptoms

\begin{tabular}{|l|l|}
\hline \multicolumn{2}{|c|}{ Access this article online } \\
\hline Quick Response Code: & Website: \\
\hline & www.ijrconline.org \\
\hline
\end{tabular}

of OSA, while 1 out of 15 has moderate-to-severe symptoms. Studies even indicate twofold to threefold greater risk in men than in women. ${ }^{[3,6]}$ The pathogenesis is multifactorial; however, anatomic defects play a major role. ${ }^{[7]}$ These OSA patients tend to have coexisting risk factors such as obesity, hypertension, diabetes mellitus, and dyslipidemia.

It has been observed that OSA acts as an independent risk factor for hypertension and insulin resistance ${ }^{[8,9]}$ Both OSA

Address for correspondence: Dr. Lt Col Ajai Kumar Tentu, Department of Pulmonary Medicine, Medical Division, Military Hospital, Namkum, Ranchi - 834 010, Jharkhand, India. E-mail: drtentu@gmail.com

This is an open access journal, and articles are distributed under the terms of the Creative Commons Attribution-NonCommercial-ShareAlike 4.0 License, which allows others to remix, tweak, and build upon the work non-commercially, as long as appropriate credit is given and the new creations are licensed under the identical terms.

For reprints contact: reprints@medknow.com

How to cite this article: Singh SK, Tentu AK, Singh S, Singh N, Dash C, Singh $\mathrm{V}$, et al. Association of metabolic syndrome in obstructive sleep apnea patients: An experience from zonal tertiary care hospital in Eastern India. Indian J Respir Care 2020;9:71-6.

Received: $31-07-2019$

Accepted: 04-12-2019

Revised: $31-10-2019$ Published: 08-01-2020 
Singh, et al.: Double jeopardy-OSA with metabolic syndrome

and obesity were observed to have negative synergistic effect over glucose metabolism. ${ }^{[8,10]}$ Further, it is detected that intermittent hypoxia leads to insulin resistance and beta-cell dysfunction. ${ }^{[10]}$ OSA and metabolic syndrome (MS) are highlighted as syndrome $\mathrm{Z}$ which can increase the risk of cardiovascular disease ${ }^{[11]}$ and insulin resistance. The possible mechanistic interactions between OSA, MS, and insulin resistance are highlighted in Figure 1. It has been observed that in India, the prevalence of syndrome $\mathrm{Z}$ ranges from $4.5 \%$ in population-based study to $79 \%$ among patients in hospital-based study. ${ }^{[12,13]}$

The National Cholesterol Education Program Adult Treatment Panel III report gives the definition of MS in view of considering the five parameters that include hypertension, insulin resistance or glucose tolerance, low-serum high-density lipoprotein cholesterol, elevated serum triglyceride levels, and abdominal obesity. ${ }^{[14]}$ The above five set variables provide for easy identification of MS. These pose a serious threat of atherosclerotic cardiovascular disease and need to be diagnosed at an early stage in order to prevent further complications. Therefore, increased awareness is the need of the hour in order to screen the patients for Syndrome $\mathrm{Z}$ and its further threatening outcomes. This study aimed at studying the patients diagnosed with OSA and its association with MS.

\section{Methodology}

The study was conducted in a tertiary care service hospital from February 2017 to March 2018. A total of 95 patients underwent 32 channel polysomnography (Alice 5) and 58 patients met the Apnea-Hypopnea Index (AHI) criteria of OSA. However, eight patients who were hemodynamically unstable were excluded. The remaining 50 patients were taken up for further investigations. After a thorough polysomnography study, the patients diagnosed with OSA were followed up on outpatient department basis monthly. They were further evaluated with detailed history about their personal details, history of habits, symptoms, and treatment history. History regarding the quality of sleep was given due importance.

The patients were screened for any comorbid illness with hematological and biochemical parameters, including the metabolic markers such as body mass index (BMI), thyroid profile, lipid profile, and blood glucose profile. The data were scored manually as per the recommendations of the American Academy of Sleep Medicine. ${ }^{[15]}$ The number of apnea and hypopnea occurring per hour of sleep is termed as AHI. AHI of 5 or more is suggestive of OSA, while a score of 5-14 suggests mild OSA, 15-30 is moderate OSA, and severe OSA has AHI more than $30^{[16]}$ [Table 1]. Excessive daytime somnolence was assessed based on Epworth sleepiness scale (ESS) $\cdot{ }^{[17]}$ Considering the time

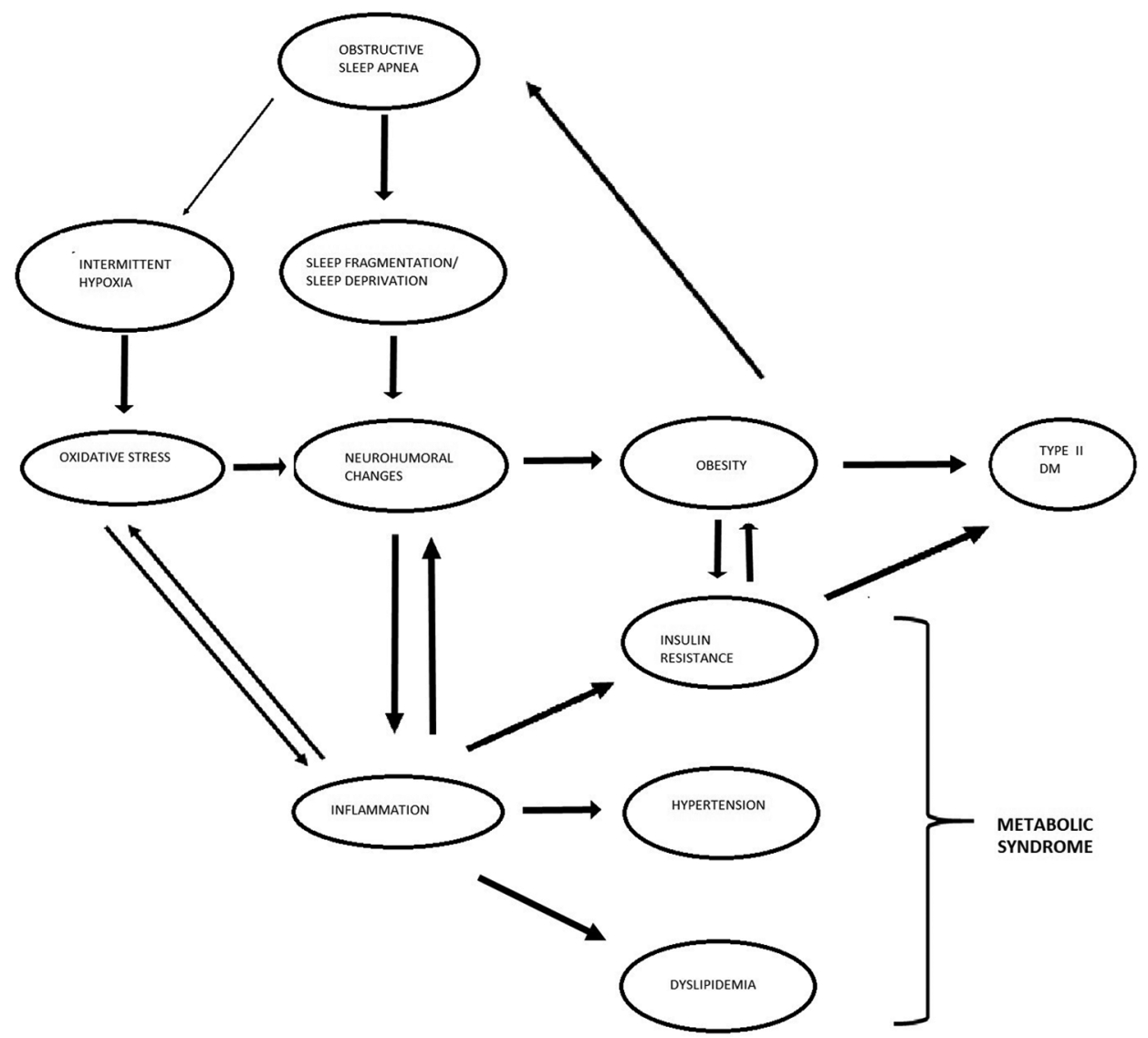

Figure 1: Possible mechanistic links between obstructive sleep apnea, metabolic syndrome, and insulin resistance 
Singh, et al.: Double jeopardy-OSA with metabolic syndrome

and feasibility, 50 patients diagnosed with OSA were investigated for the same and taken as the sample size for our descriptive study. Patients who were symptomatic but not meeting the AHI criteria and hemodynamically unstable were excluded from this study. The study was approved by the Institutional Ethics Committee and informed consent was obtained from the study participants.

\section{Statistical analysis}

Data were collected and analyzed using SPSS Inc. PASW Statistics for Windows, Version 18.0. Chicago: USA. All continuous variables were summarized in terms of mean \pm standard variation and other categorical variables were calculated as percentage. Pearson's bivariate correlation method was used to find the association. $P<0.05$ was considered statistically significant.

\section{RESULTS}

\section{Baseline characteristics}

Out of the total 50 studied OSA patients, 41 (82\%) were male and $9(18 \%)$ were female. The baseline characteristics are mentioned in Table 2 . Out of 50 patients analyzed in the study, $28(56 \%)$ were obese having BMI of more than $27 \mathrm{~kg} / \mathrm{m}^{2}$ and 22 (44\%) were found to be nonobese with BMI $<27 \mathrm{~kg} / \mathrm{m}^{2}$. Out of the 50 patients, 4 (8\%), 17 (34\%), and 29 (58\%) were detected to be suffering from mild, moderate, and severe OSA, respectively. $60 \%$ of the study population had a positive history of regular and occasional use of alcohol, while $32 \%$ had positive history of smoking.

Based on the symptomatology, $88 \%$ had daytime sleepiness, $56 \%$ had frequent night awakenings, $28 \%$ with nonrestorative sleep, 35\% with difficulty falling asleep, 56\% had morning headache, $40 \%$ had nasal congestion, $2 \%$ with personality changes, $72 \%$ with history of snoring, and $14 \%$ with nocturia. Occasional episodes of breathing pause (16\%) and choking, aspiration, gasping, and body movements were seen in $4 \%$ each, respectively [Table 3]. On further examination, $56 \%$ had hypertension and 14\% were hypothyroid, 68\% had impaired glucose tolerance, and 54\% had dyslipidemia [Table 4].

\section{Apnea-Hypopnea Index and its association with various clinical variables}

Severity of AHI with BMI: Out of 28 obese patients, $22(78.57 \%)$ had $\mathrm{AHI}>30$. Of the 22 nonobese patients, $7(31.81 \%)$ had AHI $>30$ [Table 5].

AHI with smoking: 16 of the 50 patients studied were found to be smokers of which 11 (22\%) had AHI >30 [Table 5].

AHI with treatment history and comorbidities: 17 of the patients studied were on antihypertensives only, of which 12 had AHI $>30$. All the 4 patients on Oral hypoglycemic agents (OHAs), only had AHI $>30.11$ of the 50 patients were on both OHAs and antihypertensive therapy, of these 4 had AHI $>30$. Two patients who were on other medications (1 for coronary artery disease and 1 for old cerebro Vascular accident (CVA)) had AHI $>30$. Seven of these 50 patients were
Table 1: Current criteria for the diagnosis of metabolic syndrome and sleep apnea severity classification

\begin{tabular}{ll}
\hline Factor & Criteria \\
\hline Hypertension & $\begin{array}{l}\text { Current antihypertensive therapy or BP } \\
\geq 130 / 85(\mathrm{mmHg})\end{array}$ \\
$\begin{array}{l}\text { Dyslipidemia- } \\
\text { elevated triglycerides }\end{array}$ & $\begin{array}{l}\text { Plasma triglycerides } \geq 150(\mathrm{mg} / \mathrm{dl}) \text { or } \\
\text { specific treatment for high triglycerides } \\
\text { Dyslipidemia- } \\
\text { depressed HDL }\end{array}$ \\
Obesity & women or specific treatment for low HDL \\
& Waist circumference $>37$ inches in men or \\
Glucose & $>31.5$ inches in women \\
& Fasting glucose $\geq 100(\mathrm{mg} / \mathrm{dl})$ or \\
Requirements for & previously diagnosed type 2 diabetes \\
diagnosis & Waist circumference criteria plus any two \\
No OSA & of other criteria \\
Mild & AHI $<5 / \mathrm{h}$ \\
Moderate & AHI 5-14/h \\
Severe & AHI $15-30 / \mathrm{h}$ \\
\hline OSA: Obstructive sleep & apnea, HDL: High-density lipoprotein, BP: \\
Blood pressure, AHI: Apnea-Hypopnea Index, IDF: International diabetes \\
federation
\end{tabular}

\section{Table 2: Baseline characteristics}

\begin{tabular}{lc}
\hline Variable & Subjects $(\boldsymbol{n = 5 0})$ \\
\hline Age (years) mean \pm SD & $42.54 \pm 11.242$ \\
Sex (male/female) & $41 / 9$ \\
Hypothyroidism (\%) & $7 / 50(14)$ \\
BMI (in $\left.\mathrm{kg} / \mathrm{m}^{2}\right)$, mean $\pm \mathrm{SD}$ & $27.028 \pm 2.338$ \\
AHI (per hour), mean $\pm \mathrm{SD}$ & $33.494 \pm 17.653$ \\
Waist circumference (inch) mean $\pm \mathrm{SD}$ & $37.23 \pm 2.8$ \\
Neck circumference $(\mathrm{cm})$, mean $\pm \mathrm{SD}$ & $39.7 \pm 2.3$ \\
\hline SD: Standard deviation, BMI: Body mass index, AHI: Apnea-Hypopnea \\
Index
\end{tabular}

Table 3: Symptomatology of obstructive sleep apnea

\begin{tabular}{lc}
\hline Symptoms & Frequency (\%) \\
\hline Excessive daytime sleepiness & $44(88)$ \\
Frequent night awakenings & $28(56)$ \\
Nonrestorative sleep & $14(28)$ \\
Difficulty falling asleep & $18(36)$ \\
Morning headache & $28(56)$ \\
Nasal congestion & $20(40)$ \\
Personality changes & $1(2)$ \\
Snoring & $36(72)$ \\
Nocturia & $7(14)$ \\
Breathing pauses & $8(16)$ \\
Choking & $2(4)$ \\
Aspiration & $2(4)$ \\
Gasping & $2(4)$ \\
Abnormal body movements & $2(4)$ \\
\hline
\end{tabular}

coincidentally found to have hypothyroidism of which 2 had AHI $<30$ [Table 5].

31 patients were detected to have MS [as per the criteria in Table 1] out of which 27 ( $65 \%$ of all males) were males. 
Singh, et al:: Double jeopardy-OSA with metabolic syndrome

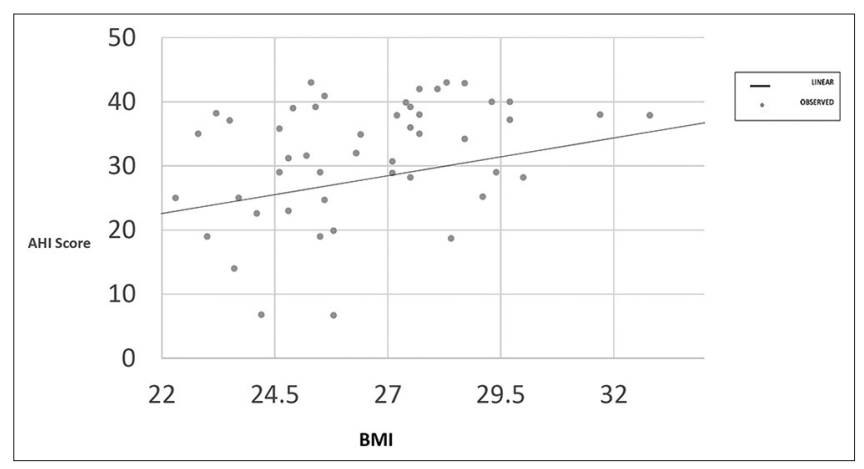

Figure 2: Scatter plot diagram showing the relationship between ApneaHypopnea Index score and body mass index

\begin{tabular}{|c|c|c|c|}
\hline S.No & Comorbidities & Frequency & $P$ \\
\hline 1 & Hypertension & 17 & 0.45 \\
\hline 2 & Hypothyroidism & 5 & 0.27 \\
\hline 3 & IGT & 20 & 0.05 \\
\hline 4 & Dyslipidemia & 14 & 0.03 \\
\hline
\end{tabular}

Table 5: Severity of Apnea-Hypopnea Index with various clinical variables

\begin{tabular}{lcc}
\hline & \multicolumn{2}{c}{ AHI } \\
\cline { 2 - 3 } & $\mathbf{3} \mathbf{3 0}$ & $>\mathbf{3 0}$ \\
\hline BMI & 15 & 7 \\
$<27$ & 6 & 22 \\
$>27$ & & \\
Smoking history & 5 & 11 \\
$\quad$ Positive & 16 & 18 \\
Negative & & \\
Treatment history & 9 & 7 \\
Nil & 5 & 12 \\
Antihypertensives only & 0 & 4 \\
Oral hypoglycemic agents only & 7 & 4 \\
Antihypertensives + oral hypoglycemic agents & 0 & 2 \\
$\quad$ Others & & \\
\hline AHI: Apnea-Hypopnea Index, BMI: Body mass index & & \\
\end{tabular}

AHI: Apnea-Hypopnea Index, BMI: Body mass index

Using Pearson's bivariate correlation method, a highly significant association $(P=0.01)$ was observed between AHI score and BMI value.

\section{Discussion}

In this study, a total of 50 patients (41 males and 9 females) were between the age group of 28 and 84 years who were diagnosed as OSA patients by standard polysomnography. They were studied for their clinical profile and were assessed for further relationship between OSA and MS. The mean age of the population was 42.5 years. The mean BMI, AHI, waist circumference, and neck circumference were $27.02 \mathrm{~kg} / \mathrm{m}^{2}$, $33.49 / \mathrm{h}, 94.5 \mathrm{~cm}$, and $39.7 \mathrm{~cm}$, respectively. Our study revealed males and those people with higher neck circumference, BMI and who are aged above 40 years are found to have association with development of OSA. Similar findings were reported in a recent Indian study. ${ }^{[18]}$

The common symptoms were excessive daytime sleepiness, snoring, frequent night awakenings, morning headache followed by others. Cases in this study had severe symptoms with many among them having associated comorbidities. This implies that a large number of patients of OSA with mild-to-moderate disease who are generally asymptomatic would remain undetected unless screened for the same. Impaired glucose tolerance (IGT)/dyslipidemia has shown an association with severity of OSA with MS; although this study was not designed to establish a cause-effect relationship.

Asian Indians have higher body fat, visceral fat and waist circumference, lower skeletal mass, thinner hips, higher rates of insulin resistance, diabetes, dyslipidemia, hypoadiponectinemia, and increased cardiovascular risk..$^{[19,20]}$ In our study, $78.6 \%$ of the obese patients were found to have severe OSA, while only $31 \%$ of nonobese individuals had severe OSA. There has been an escalating rise in obesity and MS and its subsequent cardiovascular risk in South Asian

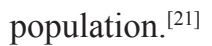

The obstructive sleep apnea syndrome (OSAS) affects $2 \%-4 \%$ of the adult population. It is a grossly underdiagnosed and undertreated condition. It is observed that OSA is also an important risk factor for the development of systemic hypertension, arrhythmias, ${ }^{[7]}$ and cerebrovascular events. ${ }^{[22]}$ The number of cardinal features of MS increases with increased severity of OSA. Out of the 50 OSA patients included in our study, 28 were known hypertensives. Apart from hypertension, 15 were known diabetic patients, 1 was an old case of CVA, and 3 had a history of ischemic heart disease. Several studies have reported high incidence of OSAS in patients of congestive heart failure. There was also significant association of OSA with MS leading to cardiovascular morbidity. ${ }^{[23]}$

In our study, $29(58 \%)$ patients were found to have severe OSA and 17 (34\%) patients with moderate OSA. Similar observations were made by Peled et al. in their study, in which out of 98 patients $53(54 \%)$ were found to have severe OSA and 27 (28\%) had moderate OSA. ${ }^{[24]}$ OSA is said to augment sympathetic nervous system activity and alter renin-angiotensin aldosterone system to cause BP derangements. A study by Sharma et al. concluded that in patients with moderate-to-severe obstructive sleep apneahypopnea syndrome, 3 months of continuous positive airway pressure (CPAP) lowers BP and partially reverses metabolic abnormalities. ${ }^{[25]}$

34 of our study patients were found to have impaired glucose tolerance. This is supported by various other cross-sectional studies that have reported a connecting link between the presence and severity of OSA and glucose tolerance, insulin resistance, and diabetes. ${ }^{[24,26-35]}$ Eventhough some studies have 
Singh, et al.: Double jeopardy-OSA with metabolic syndrome

not reported positive findings in favor of this, ${ }^{[36-38]}$ a study by Meslier et al. reports diabetes in one-third of suspected OSA patients, with increasing severity of OSA associated with IGT and insulin resistance, independently of age and BMI. ${ }^{[32]}$

Obesity is strongly associated with MS and well-known risk factor for OSA. Now with increasing epidemic of obesity, the prevalence of OSA among adults is is further on the rise. In our study, $32 \%$ patients had BMI $<25,64 \%$ had BMI ranging from 25 to 29.9 and $4 \%$ had BMI of 30 and above. Our study showed significant association between AHI score and BMI value with a $P=0.043(P<0.05)$ and was depicted in Figure 2 . The shared relationship of OSA and MS with obesity should be taken into account because it is contributing airway narrowing during sleep. Obesity, especially central obesity, is a significant risk factor which is linked to increased leptin production further leading to insulin resistance and increased development of OSA. Hence, central obesity significantly causes upper airway functional abnormality as compared to peripheral obesity with raised fat deposition around the neck. ${ }^{[39-42]}$ There are also other studies which have shown that $3 \%$ reduction in AHI with every percent of weight reduction in the individual. ${ }^{[8,43]}$ Some studies have shown that OSA is associated with carotid intimal thickening, increased levels of a variety of oxidants such as C-reactive protein, interleukin-6, tumor necrosis factor- $\alpha$, and pentraxin including oxidized low-density lipoprotein which are thought to play a key role in promoting atherosclerosis. ${ }^{[44,45]}$ In our study, 54\% of the patients were found to have dyslipidemia and $14 \%$ patients were found to have hypothyroidism who showed increased propensity toward development of MS, similar observations were made by other workers. ${ }^{[46-48]}$

The salient finding in our study revealed MS in $31(62 \%)$ patients with coexistence of OSA. Similar findings were reported by Parish et al..$^{[49]}$

\section{Limitation}

The study results had certain limitations, as it was done in a single hospital. Hence, results of the study cannot be applied to the general population. Second, this study had a small sample size.

\section{ConcLusion}

The relationship between OSA and MS still remains controversial despite substantial evidence from both clinical and population studies suggesting their link. CPAP which still remains the mainstay of OSA management, also forms the backbone of various research works trying to establish a link between the two conditions.

However, in a resource-limited setting like India, the paucity of health-care facilities with polysomnography equipment and CPAP machine, pose a major hurdle to diagnosis, evaluation, and management of OSA, thus further hindering the researchers. Identification of syndrome $\mathrm{Z}$ may bring out opportunities to interrupt pathophysiology of OSA and prevent manifestations of MS.

\section{Acknowledgments}

The authors would like to thank all the faculty and technical staff of the Department of Respiratory Medicine and Department of Laboratory Medicine, Military Hospital, Namkum, for the constant support during this study.

\section{Financial support and sponsorship}

Nil.

\section{Conflicts of interest}

There are no conflicts of interest.

\section{ReFERENCES}

1. Strollo PJ Jr., Rogers RM. Obstructive sleep apnea. N Engl J Med 1996;334:99-104.

2. Malhotra A, White DP. Obstructive sleep apnoea. Lancet 2002;360:237-45.

3. Young T, Palta M, Dempsey J, Skatrud J, Weber S, Badr S. The occurrence of sleep-disordered breathing among middle-aged adults. N Engl J Med 1993;328:1230-5.

4. Reddy EV, Kadhiravan T, Mishra HK, Sreenivas V, Handa KK, Sinha S, et al. Prevalence and risk factors of obstructive sleep apnea among middle-aged Urban Indians: A community-based study. Sleep Med 2009;10:913-8.

5. Cizza G, de Jonge L, Piaggi P, Mattingly M, Zhao X, Lucassen E, et al. Neck circumference is a predictor of metabolic syndrome and obstructive sleep apnea in short-sleeping obese men and women. Metab Syndr Relat Disord 2014;12:231-41.

6. Young T, Peppard PE, Gottlieb DJ. Epidemiology of obstructive sleep apnea: A population health perspective. Am J Respir Crit Care Med 2002;165:1217-39.

7. Somers VK, White DP, Amin R, Abraham WT, Costa F, Culebras A, et al. Sleep apnea and cardiovascular disease: An American Heart Association/American College of Cardiology Foundation Scientific Statement from the American Heart Association Council for High Blood Pressure Research Professional Education Committee, Council on Clinical Cardiology, Stroke Council, and Council on Cardiovascular Nursing. J Am Coll Cardiol 2008;52:686-717.

8. Ip MS, Lam B, Ng MM, Lam WK, Tsang KW, Lam KS. Obstructive sleep apnea is independently associated with insulin resistance. Am J Respir Crit Care Med 2002;165:670-6.

9. Nieto FJ, Young TB, Lind BK, Shahar E, Samet JM, Redline S, et al. Association of sleep-disordered breathing, sleep apnea, and hypertension in a large community-based study. Sleep Heart Health Study. JAMA 2000;283:1829-36.

10. Ryan S. Adipose tissue inflammation by intermittent hypoxia: Mechanistic link between obstructive sleep apnoea and metabolic dysfunction. J Physiol 2017;595:2423-30.

11. Wilcox I, McNamara SG, Collins FL, Grunstein RR, Sullivan CE. "Syndrome Z": The interaction of sleep apnoea, vascular risk factors and heart disease. Thorax1998;53 Suppl 3:S25-8.

12. Sharma SK, Reddy EV, Sharma A, Kadhiravan T, Mishra HK, Sreenivas V, et al. Prevalence and risk factors of syndrome $\mathrm{Z}$ in urban Indians. Sleep Med 2010;11:562-8.

13. Sharma SK, Reddy EV, Kadhiravan T, Lakshmy R, Sreenivas V. Prevalence of 'Syndrome Z' and the association of metabolic syndrome with obstructive sleep apnea in a Northern Indian population. Am J Respir Crit Care Med 2009;179:A3627.

14. Expert Panel on Detection, Evaluation, and Treatment of High Blood Cholesterol in Adults. Executive summary of the third report of the National Cholesterol Education Program (NCEP) expert panel on detection, evaluation, and treatment of high Blood cholesterol in adults (Adult Treatment Panel III). JAMA 2001;285:2486-97.

15. Buysse DJ. International Classification of Sleep Disorders: Diagnostic and Coding Manual. $2^{\text {nd }}$ ed. American Academy of Sleep Medicine, Westchester, U.S.A. 2005.

16. Flemons WW, Buysse D, Redline S. Sleep-related breathing disorders 
Singh, et al.: Double jeopardy-OSA with metabolic syndrome

in adults: Recommendations for syndrome definition and measurement techniques in clinical research. Sleep 1999;22:667-89.

17. Johns MW. A new method for measuring daytime sleepiness: The Epworth sleepiness scale. Sleep 1991;14:540-5.

18. Garg Y, Kakria N, Vardhan V, Katoch CD, Singh P. Assessing the severity of obstructive sleep apnea and systemic hypertension. JCDR 2018;12:OC10-3.

19. Deepa R, Sandeep S, Mohan V. Abdominal obesity, visceral fat, and type 2 diabetes-"Asian Indian Phenotype". In: Mohan V, Rao G, editors. Type 2 Diabetes in South Asians; Epidemiology, Risk factors and Prevention. New Delhi: Jaypee Medical Publishers; 2006.p. 138-52.

20. Yajnik CS, Fall CH, Coyaji KJ, Hirve SS, Rao S, Barker DJ, et al. Neonatal anthropometry: The thin-fat Indian baby. The Pune maternal nutrition Study. Int J Obes Relat Metab Disord 2003;27:173-80.

21. Misra A, Khurana L. The metabolic syndrome in South Asians: Epidemiology, determinants, and prevention. Metab Syndr Relat Disord 2009;7:497-514.

22. Valham F, Mooe T, Rabben T, Stenlund H, Wiklund U, Franklin KA. Increased risk of stroke in patients with coronary artery disease and sleep apnea: A 10-year follow-up. Circulation 2008;118:955-60.

23. Peker Y, Hedner J, Norum J, Kraiczi H, Carlson J. Increased incidence of cardiovascular disease in middle-aged men with obstructive sleep apnea: A 7-year follow-up. Am J Respir Crit Care Med 2002;166:159-65.

24. Peled N, Kassirer M, Shitrit D, Kogan Y, Shlomi D, Berliner AS, et al. The Association of OSA with insulin resistance, inflammation and metabolic syndrome. Respir Med 2007;101:1696-701.

25. Sharma SK, Agrawal S, Damodaran D, Sreenivas V, Kadhiravan T, Lakshmy R, et al. CPAP for the metabolic syndrome in patients with obstructive sleep apnea. N Engl J Med 2011;365:2277-86.

26. Coughlin SR, Mawdsley L, Mugarza JA, Calverley PM, Wilding JP. Obstructive sleep apnoea is independently associated with an increased prevalence of metabolic syndrome. Eur Heart J 2004;25:735-41.

27. McArdle N, Hillman D, Beilin L, Watts G. Metabolic risk factors for vascular disease in obstructive sleep apnea: A matched controlled study. Am J Respir Crit Care Med 2007;175:190-5.

28. Kono M, Tatsumi K, Saibara T, Nakamura A, Tanabe N, Takiguchi Y, et al. Obstructive sleep apnea syndrome is associated with some components of metabolic syndrome. Chest 2007;131:1387-92.

29. Tiihonen M, Partinen M, Närvänen S. The severity of obstructive sleep apnoea is Associated with insulin resistance. J Sleep Res 1993;2:56-61.

30. Strohl KP, Novak RD, Singer W, Cahan C, Boehm KD, Denko CW, et al. Insulin levels, blood pressure and sleep apnea. Sleep 1994;17:614-8.

31. Vgontzas AN, Papanicolaou DA, Bixler EO, Hopper K, Lotsikas A, Lin HM, et al. Sleep apnea and daytime sleepiness and fatigue: Relation to visceral obesity, insulin resistance, and hypercytokinemia. J Clin Endocrinol Metab 2000;85:1151-8.

32. Meslier N, Gagnadoux F, Giraud P, Person C, Ouksel H, Urban T, et al. Impaired glucose-insulin metabolism in males with obstructive sleep apnoea syndrome. Eur Respir J 2003;22:156-60.

33. Tassone F, Lanfranco F, Gianotti L, Pivetti S, Navone F, Rossetto $\mathrm{R}$, et al. Obstructive sleep apnoea syndrome impairs insulin sensitivity independently of anthropometric variables. Clin
Endocrinol (Oxf) 2003;59:374-9.

34. Peltier AC, Consens FB, Sheikh K, Wang L, Song Y, Russell JW. Autonomic dysfunction in obstructive sleep apnea is Associated with impaired glucose regulation. Sleep Med 2007;8:149-55.

35. Makino S, Handa H, Suzukawa K, Fujiwara M, Nakamura M, Muraoka S, et al. Obstructive sleep apnoea syndrome, plasma adiponectin levels, and insulin resistance. Clin Endocrinol (Oxf) 2006;64:12-9.

36. Gruber A, Horwood F, Sithole J, Ali NJ, Idris I. Obstructive sleep apnoea is independently associated with the metabolic syndrome but not insulin resistance state. Cardiovasc Diabetol 2006;5:22.

37. Sharma SK, Kumpawat S, Goel A, Banga A, Ramakrishnan L, Chaturvedi P. Obesity, and not obstructive sleep apnea, is responsible for metabolic abnormalities in a cohort with sleep-disordered breathing. Sleep Med 2007;8:12-7.

38. Davies RJ, Turner R, Crosby J, Stradling JR. Plasma insulin and lipid levels in untreated obstructive sleep apnoea and snoring; Their comparison with matched controls and response to treatment. J Sleep Res 1994;3:180-5.

39. Mortimore IL, Marshall I, Wraith PK, Sellar RJ, Douglas NJ. Neck and total body fat deposition in nonobese and obese patients with sleep apnea compared with that in control subjects. Am J Respir Crit Care Med 1998;157:280-3.

40. Young T, Peppard PE, Taheri S. Excess weight and sleep-disordered breathing. J Appl Physiol (1985) 2005;99:1592-9.

41. Schwab RJ, Pasirstein M, Pierson R, Mackley A, Hachadoorian R, Arens R, et al. Identification of upper airway anatomic risk factors for obstructive sleep apnea with volumetric magnetic resonance imaging. Am J Respir Crit Care Med 2003;168:522-30.

42. Ryan CM, Bradley TD. Pathogenesis of obstructive sleep apnea. J Appl Physiol (1985) 2005;99:2440-50.

43. Davies RJ, Ali NJ, Stradling JR. Neck circumference and other clinical features in the diagnosis of the obstructive sleep apnoea syndrome. Thorax 1992;47:101-5.

44. Ciccone MM, Scicchitano P, Zito A, Cortese F, Boninfante B, Falcone VA, et al. Correlation between inflammatory markers of atherosclerosis and carotid intima-media thickness in obstructive sleep apnea. Molecules 2014;19:1651-62.

45. Zychowski KE, Sanchez B, Pedrosa RP, Lorenzi-Filho G, Drager LF, Polotsky VY, et al. Serum from obstructive sleep apnea patients induces inflammatory responses in coronary artery endothelial cells. Atherosclerosis 2016;254:59-66.

46. Roos A, Bakker SJ, Links TP, Gans RO, Wolffenbuttel BH. Thyroid function is Associated with components of the metabolic syndrome in euthyroid subjects. J Clin Endocrinol Metab 2007;92:491-6.

47. Iqbal A, Jorde R, Figenschau Y. Serum lipid levels in relation to serum thyroid-stimulating hormone and the effect of thyroxine treatment on serum lipid levels in subjects with subclinical hypothyroidism: The Tromsø Study. J Intern Med 2006;260:53-61.

48. Asvoid BO, Vatten LJ, Nilsen TI, Bjoro T. The Association between TSH within the reference range and serum lipid concerntrations in a population based study. The HUNT Study. Eur J Endocrinol 2007;156:707.

49. Parish JM, Adam T, Facchiano L. Relationship of metabolic syndrome and obstructive sleep apnea. J Clin Sleep Med 2007;3:467-72. 